\title{
Aplikasi Chemical Virtual Lab Dengan Menggunakan Bahasa Pemrograman Java Serta Mengimplementasi JavaFX
}

\author{
Ragil Rynaldo Meyer ${ }^{1}$, Yayan Hendrian² \\ ${ }^{1,2}$ Universitas Bina Sarana Informatika \\ e-mail: ${ }^{1}$ meyer.ananda@gmail.com, ${ }^{2}$ yayan.yhn@bsi.ac.id
}

\begin{abstract}
Abstrak - Teknologi telah banyak membantu dalam mengumpulkan, memproses, dan memvisualisasikan informasi. Dalam bidang pendidikan, teknologi dapat membantu memberikan sarana pembelajaran yang berguna bagi para kalangan pelajar dan akademisi. Hal ini dibuktikan oleh hasil penelitian beberapa orang sebelumnya. Aplikasi Virtual Chemical Lab merupakan salah satu sarana pembelajaran yang menggunakan teknologi pemrograman Java. Fitur yang terdapat pada aplikasi ini berlandaskan kepada teori yang di dapat dari sumber buku-buku, terutama buku yang berjudul "Chemical Principle: The Quest for Insight." Fitur utama pada aplikasi ini adalah memprediksi produk hasil reaksi kimia yang diuji kembali dengan mencari informasi pada basis data yang disediakan oleh National Institutes of Health dan National Cancer Institute. Fitur pendukung lainnya adalah tabel periode dengan berbagai informasi dari informasi atomik sampai kepada sejarah penemuan unsur-unsur atom; dan informasi bentuk geometri 3 dimensi, geometri 2 dimensi, dan informasi deskriptif bentuk fisik dari suatu kompon atau molekul yang juga diperoleh dari basis data yang sama dengan yang telah disebutkan sebelumnya.
\end{abstract}

Kata Kunci: Virtual Lab, Kimia, Java, JavaFX, Aplikasi

Abstract - Technology has helped a lot in collecting, processing, and visualizing information. In the field of education, technology can help to provide a useful learning tool for students and academics. It explained by the results of some previous research. Virtual Chemical Lab application is one of learning environment using Java programming technology. The features contained in this application are based on the theory from the books, especially the book entitled "Chemical Principle: The Quest for Insight." The main feature in this application is to predict the product of chemical reactions and test it by finding information on database provided by the National Institutes of Health and the National Cancer Institute. Another feature is the period table with various information from atomic information to the history of the atomic element discoveries; and 3-dimensional geometry information, 2-dimensional geometry, and descriptive physical form information of a compound or molecule, also obtained from the same database as mentioned above.

Key Words: Virtual Lab, Chemical, Java, JavaFX, Application

\section{PENDAHULUAN}

Dalam bidang pendidikan, teknologi membantu dalam hal belajar mengajar. Modul yang selama ini digunakan dalam proses pembelajaran masih memiliki layout sederhana dan isi yang hanya berupa materi pokok saja. Modul seperti ini membuat siswa cenderung merasa bosan dalam mempelajari materi pada setiap pokok bahasan sehingga diperlukan suatu pengembangan media pembelajaran berupa modul yang dapat menarik minat siswa pada materi kimia (Sari, Saputro, \& Catur, 2014).

(Nurrokhmah \& Sunarto, 2013) menjelaskan, terjadi peningkatan dalam penguasaan konsep materi kimia menggunakan aplikasi Virtual Labs. Sama halnya penelitian yang dilakukan oleh (Anisah,
2013), aplikasi virtual laboratory dalam pembelajaran kimia memberikan pengaruh positif terhadap hasil pembelajaran siswa baik kemampuan kognitif, afektif dan psikomotorik. (Sugiana, Harjono, \& Sahidu, 2016) juga menjelaskan, terjadi peningkatan pembelajaran siswa berupa konsep hukum fisika yang diperbantukan dengan aplikasi laboratorium virtual.

(Yulianti \& Khanafiyah, 2012) menjelaskan salah satu bagian e-learning adalah virtual experiment. Sistem virtual experiment berfungsi sebagai mediator dan katalisator dalam belajar dalam sistem ini peranan alat digantikan oleh software pembelajara.

Michaela M dalam (Jaya, 2012) menjelaskan bahwa sebuah laboratorium virtual didefinisikan 
sebagai lingkungan yang interaktif untuk menciptakan dan melakukan eksperimen simulasi: taman bermain untuk bereksperimen. Ini terdiri dari domain dependent program simulasi, unit eksperimental disebut objek yang mencakup file data, alat yang beroperasi pada benda-benda, dan buku referensi

(Felintina Yuniarti, Pramesti Dewi $\square, 2012$ ) dalam hasil penelitiannya mengatakan bahwa virtual laboratory memiliki tingkat keberterimaan "sangat mendukung" oleh siswa dan guru serta mencapai ketuntasan klasikal 88,24\%.

Atom dan molekul merupakan salah satu pokok bahasan dalam pembelajaran kimia yang membahas tentang partikel-partikel terkecil dari suatu benda yang tidak dapat dilihat dengan mata. Pada tingkat perguruan tinggi, atom dan molekul diajarkan agar mahasiswa mengetahui konsep-konsep kimia yang saling berkaitan (Sabarni, 2014).

Kemampuan berfikir logis dan sikap sains mengacu terhadap bukti (evidence) dan tidak sematamata mengandalkan intuisi (intuition). Bukti yang dapat direpesentasikan secara matematis dan diuji secara empiris serta klausa sebab-akibat atas segala sesuatu yang terjadi. Tetapi, dalam mempelajari ilmu kimia, apalah arti dari suatu rumus kimia ketika tidak dapat diuji kebenarannya. Salah satu contohnya ketika kita mengira air $\left(\mathrm{H}_{2} \mathrm{O}\right)$ terdiri dari molekulmolekul yang tidak dapat terbakar, sama seperti sifat air yang dapat memadamkan api. Tetapi, faktanya adalah molekul hidrogen mudah terbakar, sedangkan molekul oksigen diperlukan dalam pembakaran.

Pengujian tentunya membutuhkan lebih dari sekedar alat-alat pendukung yang berkualitas, sarana, dan prasarana yang memadai. Pengujian jelas menghabiskan waktu, sumber daya, serta dapat memberikan dampak buruk terhadap lingkungan sekitar maupun terhadap orang yang menguji.

Dengan menggunakan teknologi pemrograman perangkat lunak dan informasi yang didapat dari sumber jurnal ilmiah, buku, dan basis data untuk semua bahan kimia, kita dapat membuat suatu aplikasi yang dapat memprediksi serta memberikan informasi mengenai reaksi kimia, produk hasil dari reaksi kimia serta informasi yang terkait dengan suatu molekul atau kompon. Hal ini tentunya dapat digunakan sebagai bahan informasi serta sarana edukasi.

\section{METODE PENELITIAN}

Beberapa metode yang penulis gunakan dalam penelitian ini antara lain:

1. Penelitian pustaka

Landasan teori dari setiap fitur yang ada di dalam aplikasi ini berasal dari standar dan aturan yang penulis temukan dari jurnal ilmiah dan buku-buku terkait. Serta ditambah dengan dokumen dari situs resmi terkait dengan pembangunan aplikasi, design aplikasi, dan akses basis data.

\section{Perancangan aplikasi}

Dalam melakukan perancangan aplikasi, penulis menggunakan program java dan java fx. (Rozi \& Sukmana, 2017) JavaFX murni ditulis dalam bahasa Java dan dapat dijalankan disemua bahasa pemrograman yang dapat dijalankan di JVM, yaitu : Java, Ruby, dan JRuby. Informasi mengenai unsur-unsur atom dapat diperoleh melalui tabel periodik. (Musalwahyuni, Kasmawi, \& Mawarni, 2017) mengatakan bahwa aplikasi dapat mempermudah menghapal nama unsur. Tabel periodik unsur diambil dari (Junie, 2017). Tabel periodik pada umumnya memuat informasi mengenai nomor atom, massa atom, nama atom, simbol atom, grup atom, dan nomor IUPAC. Tetapi, dalam melakukan prediksi produk hasil reaksi kimia, dibutuhkan informasi seperti keelektro-negatifitas dan charge. Oleh karena itu, sumber informasi tambahan diperlukan untuk dapat memenuhi kebutuhan dari aplikasi Chemical Virtual Lab. Tidak hanya itu, informasi seperti nama penemu dan tahun ditemukannya akan dapat menambah khasanah dari tabel periodik. sumber informasi tambahan untuk tabel periodik diambil dari Royal Society of Chemistry (RSC) yaitu organisasi yang memfokuskan kepada penelitian bidang keilmuan kimia. Alamat situs dari RSC dapat dikunjungi di https://www.rsc.org dengan alamat situs untuk informasi tambahan tabel periode di https://www.rsc.org/periodic-table.

\section{Pengujian Terhadap Hasil Prediksi}

Chemical Virtual Lab mempunyai fitur utama untuk memprediksi produk hasil reaksi kimia, yaitu reaksi Synthesis, Single Replacement, Double Replacement, Combustion, serta Acid/Base. Tetapi dalam kenyataannya, reaksi kimia adalah sesuatu yang lebih kompleks.

\section{HASIL DAN PEMBAHASAN}

Seperti telah dijelaskan sebelumnya mengenai fitur dari aplikasi ini, setiap fitur akan dipisahkan menjadi 3 menu utama. Menu Tabel Periode akan memvisualisasikan tabel periode dengan tambahan informasi; menu Prediksi yang akan memprediksi produk dari reaksi kimia Synthesis, Single Replacement, Double Replacement, Combustion dan Acid/Base; serta menu Geometri yang memvisualisasikan bentuk geometri 2 dimensi dan 3 dimensi serta tambahan informasi deskriptif.

\section{Desain}

Penulis mendesain beberapa spesifikasi agar memudahkan dalam perancangan programnya. Berikut ini adalah detailnya.

\section{a) Spesifikasi Bentuk Masukan Menu Tabel Periode}


Di dalam menu ini, pengguna tidak memasukkan teks apapun selain memilih unsur pada tabel periode untuk ditampilkan informasinya. Informasi yang dimasukkan pada menu ini berasal dari berkas dokumen elements.csv (comma separated value) yang berada di dalam direktori yang sama dengan aplikasi ini.

Tabel 1. Spesifikasi Berkas Digital elements.csv

\begin{tabular}{|c|c|c|}
\hline Nama Kolom & $\begin{array}{l}\text { Tipe } \\
\text { Data }\end{array}$ & Penjelasan \\
\hline No & Integer & Nomor Atom \\
\hline Name & String & Nama Atom \\
\hline Mass & Double & Massa Atom \\
\hline Group & String & $\begin{array}{l}\text { Nomor Group } \\
\text { Atom } \\
\text { berdasarkan } \\
\text { American } \\
\text { Standard }\end{array}$ \\
\hline IUPAC & Integer & $\begin{array}{l}\text { Nomor Group } \\
\text { berdasarkan } \\
\text { IUPAC }\end{array}$ \\
\hline Period & Integer & $\begin{array}{l}\text { Nomor Periode } \\
\text { Atom }\end{array}$ \\
\hline Type & String & Tipe Unsur Atom \\
\hline Ionization Energy & Double & $\begin{array}{l}\text { Nilai Energi } \\
\text { Ionisasi Atom }\end{array}$ \\
\hline Electronegativity & Double & $\begin{array}{l}\text { Nilai Ke-elektro- } \\
\text { negatifitas Atom }\end{array}$ \\
\hline Discoverer & String & Nama Penemu \\
\hline Year & String & $\begin{array}{l}\text { Tahun } \\
\text { Ditemukan }\end{array}$ \\
\hline Valence & Integer & $\begin{array}{l}\text { Jumlah Elektron } \\
\text { terluar (valensi) }\end{array}$ \\
\hline Charge & String & $\begin{array}{l}\text { Nilai Elektron } \\
\text { yang dilepaskan } \\
\text { atau diterima }\end{array}$ \\
\hline
\end{tabular}

Sumber: dokumen penulis

\section{b) Spesifikasi Bentuk Masukan Menu Prediksi}

Pada menu ini, pengguna dapat melakukan prediksi dengan memilih di antara 2 kolom daftar ion, yaitu daftar ion kation dan daftar ion anion untuk prediksi reaksi kimia Synthesis. Dimana daftar tersebut dimasukkan informasi dari berkas digital elements.csv (lihat Tabel III.1) dan berkas digital polyatomic.csv yang terdapat di dalam direktori yang sama dengan berkas digital elements.csv. Selain itu pengguna juga dapat memasukkan teks berupa formula struktur kimia ke dalam 2 textbox yang disediakan untuk prediksi reaksi kimia selain Synthesis.

Tabel 2. Spesifikasi Berkas Digital polyatomic.csv

\begin{tabular}{|l|l|ll|}
\hline $\begin{array}{c}\text { Nama } \\
\text { Kolom }\end{array}$ & \multicolumn{1}{c|}{$\begin{array}{c}\text { Tipe } \\
\text { Data }\end{array}$} & \multicolumn{1}{|c|}{ Penjelasan } \\
\hline Ion & String & $\begin{array}{l}\text { Formula } \\
\text { Poliatomik }\end{array}$ & Struktur \\
\hline
\end{tabular}

\begin{tabular}{|l|l|l|}
\hline Name & String & Nama Poliatomik \\
\hline Charge & Integer & $\begin{array}{l}\text { Nilai elektron yang } \\
\text { dilepaskan atau diterima }\end{array}$ \\
\hline
\end{tabular}

Sumber: dokumen penulis

Untuk format teks yang valid sebagai masukan pada 2 textbox yang disediakan adalah sebagai berikut:

a. Formula Struktur Standar. Contoh:
1) $\mathrm{H}_{2} \mathrm{SO}_{4}$
2) $\mathrm{H}_{2} \mathrm{O}$
3) $\mathrm{CaCO}_{3}$

b. Formula Struktur Tidak Standar. Contoh:
1) $\mathrm{HSO}_{4}$

2) $\mathrm{MnSO}_{4}$

Sedangkan untuk kombinasi teks masukkan agar prediksi yang diinginkan dari reaksi kimia dapat diketahui harus memenuhi formula sebagai berikut:

a. Reaksi Single Replacement

1) Kation + kompon (kation + anion) Contoh: $\mathrm{Mg}+\mathrm{AlCl}$

2) Kompon (kation + anion) + kation Contoh: $\mathrm{AlCl}+\mathrm{Mg}$

b. Reaksi Double Replacement, Combustion, dan Acid/Base

1) Kompon (kation + anion) + kompon (kation + anion) Contoh: $\mathrm{H}_{2} \mathrm{SO}_{4}+\mathrm{NaOH}$

\section{c) Spesifikasi Bentuk Masukan Menu Geometri}

Pada menu ini, pengguna dapat memasukkan teks ke dalam textbox yang tersedia. Format teks yang dimasukkan dapat berupa formula struktur yang telah dijelaskan sebelumnya atau nama dari molekul atau kompon dalam bahasa Inggris atau nama berdasarkan penamaan IUPAC. Contoh: Aspirin, Glucose, Methane, Iron Oxide, dihydrogen sulphate, dan lainlain.

\section{d) Spesifikasi Bentuk Masukan Web API Chemical Open Database}

Bentuk masukan yang valid untuk dapat mengakses informasi dari Web API Chemical Open Database, yaitu:

a. Web API NIC

https://cactus.nci.nih.gov/chemical/structure/ $\underline{x x x}$ lyyy

Digunakan untuk mencari informasi mengenai suatu molekul/kompon dimana $\underline{x x x}$ adalah masukan yang dapat berupa formula struktur atau nama IUPAC molekul/kompon; dan yyy adalah bentuk keluaran.

b. Web API NIH

https://pubchem.ncbi.nlm.nih.gov/rest/pug/com pound/name/ $x x x / y y y$

Digunakan untuk mencari informasi mengenai suatu molekul/kompon dimana $\underline{x x x}$ adalah masukan yang dapat berupa formula struktur atau nama IUPAC molekul/kompon; dan yyy adalah bentuk keluaran. 
c. https://pubchem.ncbi.nlm.nih.gov/rest/pug_view /data/compound $/ \underline{x x x} / \underline{y y y}$ ?heading=Physical+Des cription

Digunakan untuk mencari informasi deskripsi bentuk fisik dimana $\underline{x x}$ adalah masukan berupa nomor CID, yaitu nomor kompon yang tersimpan pada database NIH dan yyy bentuk keluaran

\section{e) Spesifikasi Bentuk Keluaran Menu Tabel Periode}

Bentuk keluaran pada menu ini ialah jendela yang berisi seluruh informasi yang didapatkan dari berkas digital elements.csv tentang unsur yang dipilih sebelumnya pada tabel periode.

\section{f) Spesifikasi Bentuk Keluaran Menu Prediksi}

Bentuk keluaran pada menu ini ialah Teks Jenis Reaksi, Teks Produk hasil reaksi, dan Teks informasi mengenai produk berupa nama kompon, nama kompon berdasarkan penamaan IUPAC, serta nomor registri CAS (Chemistry Abstract Structure) yang didapatkan dari NIC atau NIH.

Tabel 3. Keluaran Hasil Prediksi

\begin{tabular}{|l|l|}
\hline $\begin{array}{c}\text { Teks Keluaran } \\
\text { Jenis Reaksi }\end{array}$ & \multicolumn{1}{|c|}{ Penjelasan } \\
\hline SYNTHESIS & $\begin{array}{l}\text { Reaksi yang terjadi adalah } \\
\text { Synthesis }\end{array}$ \\
\hline $\begin{array}{l}\text { SINGLE_REPL } \\
\text { ACEMENT }\end{array}$ & $\begin{array}{l}\text { Reaksi yang terjadi adalah } \\
\text { Single Replacement }\end{array}$ \\
\hline $\begin{array}{l}\text { DOUBLE_REPL } \\
\text { ACEMENT }\end{array}$ & $\begin{array}{l}\text { Reaksi yang terjadi adalah } \\
\text { Double Replacement }\end{array}$ \\
\hline COMBUSTION & $\begin{array}{l}\text { Reaksi yang terjadi adalah } \\
\text { Combustion }\end{array}$ \\
\hline ACID_BASE & $\begin{array}{l}\text { Reaksi yang terjadi adalah } \\
\text { Acid/Base }\end{array}$ \\
\hline
\end{tabular}

Sumber: dokumen penulis

Tabel 4. Keluaran Informasi Produk

\begin{tabular}{|l|l|}
\hline Nama Informasi & \multicolumn{1}{c|}{ Contoh Teks } \\
\hline Nama Kompon & Sulfuric Acid \\
\hline Nama IUPAC & Dihydrogen Sulphate \\
\hline $\begin{array}{l}\text { Nomor Registri } \\
\text { CAS }\end{array}$ & $7440-41-7$ \\
\hline
\end{tabular}

Sumber: dokumen penulis

\section{g) Spesifikasi Bentuk Keluaran Menu Geometri}

Pada menu ini, bentuk keluarannya adalah visualisasi bentuk geometri 3 dimensi dengan menggunakan webview, visualisasi bentuk geometri 2 dimensi berupa gambar, dan informasi deskriptif dari molekul dan kompon yang dicari.

Tabel 5. Keluaran Informasi Deskriptif Fisik

\begin{tabular}{|c|c|}
\hline $\begin{array}{c}\text { Nama } \\
\text { Informasi }\end{array}$ & Penjelasan \\
\hline $\begin{array}{l}\text { Deskripsi } \\
\text { Fisik }\end{array}$ & $\begin{array}{l}\text { Mendeskripsikan bentuk fisik dan } \\
\text { sumber informasi }\end{array}$ \\
\hline $\begin{array}{l}\text { Nomor } \\
\text { Deskripsi }\end{array}$ & $\begin{array}{l}\text { Nomor Deskripsi yang ada pada } \\
\text { database }\end{array}$ \\
\hline
\end{tabular}

Sumber: dokumen penulis

\section{h) Spesifikasi Bentuk Keluaran Web API Chemical Open Database}

Seperti telah dijelaskan sebelumnya pada Spesifikasi Bentuk Masukan Web API Chemical Open Database, berikut adalah format keluaran yang valid:

Tabel 6. Format Keluaran yang Valid Untuk Web API NCI

\begin{tabular}{|l|l|}
\hline \multicolumn{1}{|c|}{$\begin{array}{c}\text { Format } \\
\text { Keluaran }\end{array}$} & \multicolumn{1}{|c|}{ Penjelasan } \\
\hline Png & $\begin{array}{l}\text { Berupa gambar geometri 2 } \\
\text { dimensi atau struktur lewis } \\
\text { (format *png) }\end{array}$ \\
\hline Sdf & $\begin{array}{l}\text { Berupa berkas digital sdf yang } \\
\text { berisi data koordinat yang } \\
\text { membentuk bentuk 3 dimensi } \\
\text { (format *sdf) }\end{array}$ \\
\hline stdinchikey & $\begin{array}{l}\text { Berupa teks kunci Standard InchI } \\
\text { (International Chemical } \\
\text { Identifier) (teks) }\end{array}$ \\
\hline Cas & $\begin{array}{l}\text { Nomor CAS Registry Number } \\
\text { (teks) }\end{array}$ \\
\hline iupac_name & Nama IUPAC (teks) \\
\hline
\end{tabular}

Sumber: dokumen penulis

Tabel 7. Format Keluaran yang Valid Untuk Web API NIH

\begin{tabular}{|l|l|}
\hline $\begin{array}{c}\text { Format } \\
\text { Keluaran }\end{array}$ & \multicolumn{1}{|c|}{ Penjelasan } \\
\hline PNG & $\begin{array}{l}\text { Berupa gambar geometri 2 dimensi } \\
\text { atau struktur lewis (format *png) }\end{array}$ \\
\hline SDF & $\begin{array}{l}\text { Berupa berkas digital sdf yang berisi } \\
\text { data koordinat yang membentuk } \\
\text { bentuk 3 dimensi (format *sdf) }\end{array}$ \\
\hline XML & $\begin{array}{l}\text { Berupa berkas digital Extensible } \\
\text { Markup Language (format *xml) }\end{array}$ \\
\hline JSON & $\begin{array}{l}\text { Berupa berkas digital Java Script } \\
\text { Object Notation (format *json) }\end{array}$ \\
\hline
\end{tabular}

Sumber: dokumen penulis

i) Spesifikasi File Menu Utama

Tabel 8. File dan Penjelasan Menu Utama

\begin{tabular}{|c|l|}
\hline \multicolumn{1}{|c|}{ Nama File } & \multicolumn{1}{|c|}{ Penjelasan } \\
\hline MainMenu.fxml & $\begin{array}{l}\text { Merupakan file } \\
\text { FXML atau file xml } \\
\text { layout JavaFX, yang } \\
\text { mendeskripsikan } \\
\text { semua elemen grafis }\end{array}$ \\
\hline
\end{tabular}




\begin{tabular}{|l|l|}
\hline & dan peletakkannya \\
yang ada di Menu \\
Utama File ini \\
nantinya yang akan \\
membentuk \\
antarmuka grafis. \\
\hline \multirow{5}{*}{ MainMenuController.java } & Merupakan Java \\
& Class yang \\
mengontrol setiap \\
Event dan \\
memanipulasi grafis \\
antarmuka \\
Menu Utama. \\
\hline
\end{tabular}

Sumber: dokumen penulis

\section{j) Spesifikasi File Menu Tabel Periode}

Tabel 9. File dan Penjelasan Menu Tabel Periode

\begin{tabular}{|l|l|}
\hline Nama File & \multicolumn{2}{|c|}{ Penjelasan } \\
\hline & Merupakan file \\
& FXML atau file \\
& xml layout \\
& JavaFX, yang \\
& mendeskripsikan \\
PeriodTables.fxml & semua elemen \\
& grafis dan \\
& peletakkannya \\
& yang ada di Menu \\
& Tabel Periode. File \\
& ini nantinya yang \\
& akan membentuk \\
& antarmuka grafis. \\
\hline & Merupakan Java \\
& Class yang \\
& mengontrol setiap \\
PeriodTablesController.java & Event dan \\
& memanipulasi \\
& antarmuka grafis \\
& Menu Tabel \\
& Periode. \\
\hline
\end{tabular}

Sumber: dokumen penulis

\section{k) Spesifikasi File Menu Prediksi}

Tabel 10. File dan Penjelasan Menu Prediksi

\begin{tabular}{|c|l|}
\hline Nama File & \multicolumn{1}{|c|}{ Penjelasan } \\
\hline & Merupakan file \\
& FXML atau file \\
& xml layout \\
& JavaFX, yang \\
& mendeskripsikan \\
PredictionTab.fxml & semua elemen \\
& grafis dan \\
& peletakkannya \\
& yang ada di Menu \\
& Prediksi. File ini \\
& nantinya yang \\
& akan membentuk \\
& antarmuka grafis. \\
\hline
\end{tabular}

\begin{tabular}{|l|l|}
\hline & Merupakan Java \\
Class yang \\
mengontrol setiap \\
medionTabController.java dan \\
Event \\
memanipulasi \\
antarmuka grafis \\
Menu Prediksi.
\end{tabular}

Sumber: dokumen penulis

\section{I) Spesifikasi File Menu Geometri}

Tabel 11. File dan Penjelasan Menu Geometri

\begin{tabular}{|c|c|}
\hline Nama File & Penjelasan \\
\hline Atom3DViewer.fxml & $\begin{array}{l}\text { Merupakan file } \\
\text { FXML atau file } \\
\text { xml layout } \\
\text { JavaFX, yang } \\
\text { mendeskripsika } \\
\text { n semua elemen } \\
\text { grafis dan } \\
\text { peletakkannya } \\
\text { yang ada di } \\
\text { Menu Geometri. } \\
\text { File ini nantinya } \\
\text { yang akan } \\
\text { membentuk } \\
\text { antarmuka } \\
\text { grafis. }\end{array}$ \\
\hline $\begin{array}{l}\text { Atom3DViewerController.jav } \\
\text { a }\end{array}$ & $\begin{array}{l}\text { Merupakan Java } \\
\text { Class yang } \\
\text { mengontrol } \\
\text { setiap Event dan } \\
\text { memanipulasi } \\
\text { antarmuka grafis } \\
\text { Menu Geometri. }\end{array}$ \\
\hline
\end{tabular}

Sumber: dokumen penulis

\section{m) Spesifikasi File Lain-lain}

Tabel 12. File dan Penjelasan File Lain-lain

\begin{tabular}{|c|c|}
\hline Nama File & Penjelasan \\
\hline Bonding.java & $\begin{array}{l}\text { Merupakan Java Enum } \\
\text { yang berisi Constant } \\
\text { nama Ikatan. Dengan } \\
\text { mensuplai } 2 \text { Objek } \\
\text { (Atom atau Polyatom) } \\
\text { dapat diketahui ikatan } \\
\text { dari suatu molekul. }\end{array}$ \\
\hline Reaction.java & $\begin{array}{l}\text { Merupakan Java Enum } \\
\text { yang berisi Constant } \\
\text { nama reaksi kimia. } \\
\text { Dengan mensuplai } \\
\text { formula struktur dapat } \\
\text { diketahui nama reaksi } \\
\text { yang terjadi. }\end{array}$ \\
\hline Types.java & $\begin{array}{l}\text { Merupakan Java Enum } \\
\text { yang berisi Constant } \\
\text { nama jenis atom atau } \\
\text { poliatomik. Dengan } \\
\text { mensuplai }\end{array}$ \\
\hline
\end{tabular}




\begin{tabular}{|c|c|}
\hline & $\begin{array}{l}\text { (Atom/Polyatom) dapat } \\
\text { diketahui jenis atom atau } \\
\text { poliatomik }\end{array}$ \\
\hline ElementReader.java & $\begin{array}{l}\text { Merupakan Java Class } \\
\text { yang berfungsi untuk } \\
\text { membaca berkas digital } \\
\text { elements.csv dan } \\
\text { menghasilkan } \\
\text { LinkedHashMap<String } \\
\text {, Object> dimana String } \\
\text { berisi nama atom dan } \\
\text { Object berisi objek } \\
\text { Atom }\end{array}$ \\
\hline $\begin{array}{l}\text { PolyatomicReader.jav } \\
\text { a }\end{array}$ & $\begin{array}{l}\text { Merupakan Java Class } \\
\text { yang berfungsi untuk } \\
\text { membaca berkas digital } \\
\text { elements.csv dan } \\
\text { menghasilkan } \\
\text { LinkedHashMap<String } \\
\text {, Object> dimana String } \\
\text { berisi nama atom dan } \\
\text { Object berisi objek } \\
\text { Atom }\end{array}$ \\
\hline FileDownload.java & $\begin{array}{l}\text { Merupakan Java Class } \\
\text { yang berfungsi untuk } \\
\text { mendownload berkas } \\
\text { digital dari NIH dan } \\
\text { NIC. }\end{array}$ \\
\hline Atom.java & $\begin{array}{l}\text { Merupakan Java Class } \\
\text { yang berfungsi untuk } \\
\text { membentuk objek Atom, } \\
\text { yaitu objek yang berisi } \\
\text { semua informasi/nilai } \\
\text { hasil pembacaan berkas } \\
\text { digital elements.csv }\end{array}$ \\
\hline Polyatom.java & $\begin{array}{lr}\text { Merupakan Java } & \text { Class } \\
\text { yang berfungsi } & \text { untuk } \\
\text { membentuk } & \text { objek } \\
\text { Polyatom, yaitu } & \text { objek } \\
\text { yang berisi } & \text { semua } \\
\text { informasi/nilai hasil } & \text { hembacaan berkas } \\
\text { pem.csv } \\
\text { digital polyatom. }\end{array}$ \\
\hline NotationToCode.java & $\begin{array}{l}\text { Merupakan Java Class } \\
\text { yang berfungsi untuk } \\
\text { merubah formula } \\
\text { struktur menjadi } \\
\text { ArrayList<String }> \\
\text { dimana String } \\
\text { merupakan symbol dari } \\
\text { objek Atom atau } \\
\text { Polyatom. Contoh: } \mathrm{H}_{2} \mathrm{O} \\
\text { menjadi }[\mathrm{H}, \mathrm{H}, \mathrm{O}] .\end{array}$ \\
\hline Compound.java & $\begin{array}{lr}\text { Merupakan Java } & \text { Class } \\
\text { yang berfungsi } & \text { untuk } \\
\text { membentuk } & \text { objek } \\
\text { kompon dimana di } & \text { dalamnya } \\
\text { fungsi } & \text { terdapat } \\
\text { memastikan } & \text { susuntuk } \\
\end{array}$ \\
\hline
\end{tabular}

\begin{tabular}{|l|l|}
\hline & $\begin{array}{l}\text { kompon valid (terdiri } \\
\text { dari kation dan anion). }\end{array}$ \\
\hline NotationUtils.java & $\begin{array}{l}\text { Merupakan Java Class } \\
\text { yang di dalamnya } \\
\text { terdapat fungsi untuk } \\
\text { melakukan manipulasi } \\
\text { notasi kimia. }\end{array}$ \\
\hline
\end{tabular}

Sumber: dokumen penulis

\section{HIPO}

Berikuit ini adalah rancangan program dalam bentuk HIPO.

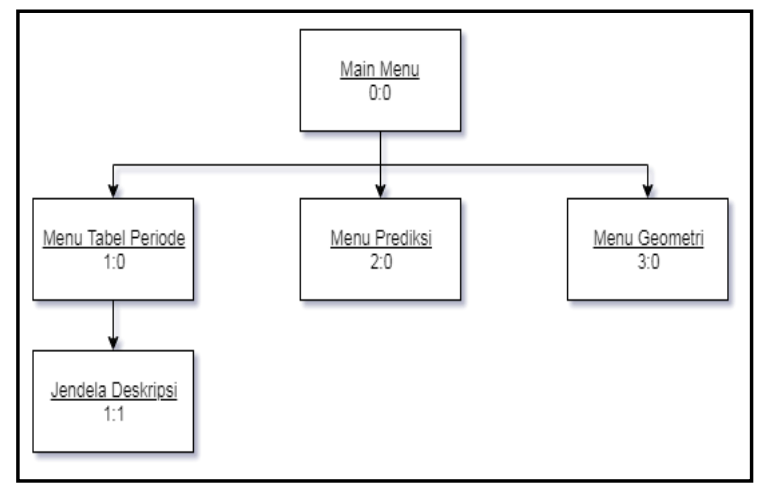

Sumber: dokumen penulis

Gambar 1. HIPO Chemical Virtual Lab

\section{Spesifikasi Program}

\section{a) Tampilan Antarmuka Grafis Menu Utama dan Penjelasannya}

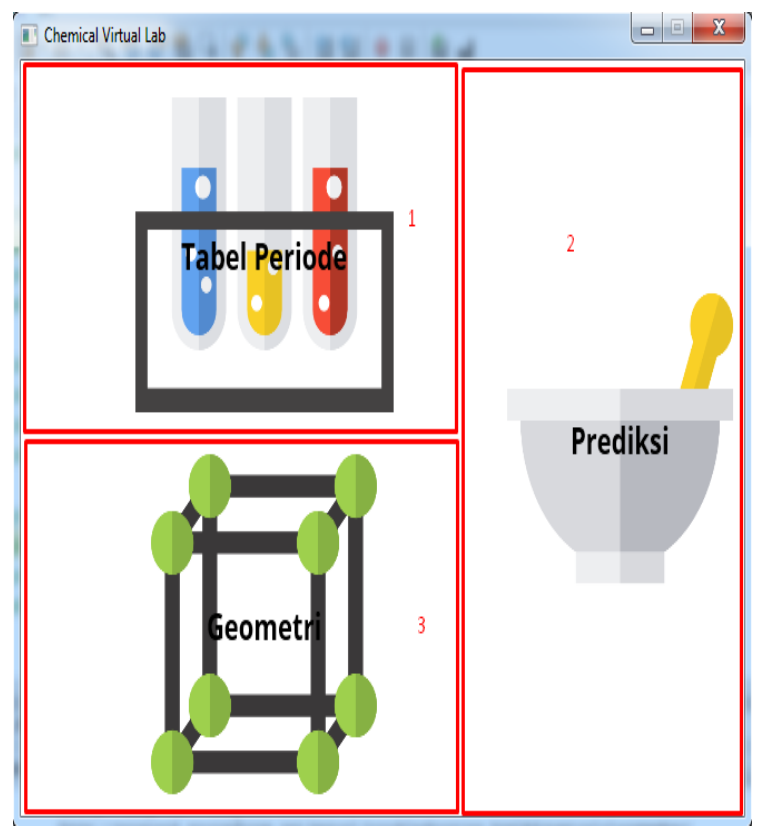

Sumber: dokumen penulis

Gambar 2. Antarmuka Grafis Menu Utama 
Penjelasan gambar:

Nomor satu (1) merupakan Menu Tabel Periode. Klik pada gambar untuk membuka jendela Menu Tabel Periode. Nomor dua (2) merupakan Menu Prediksi. Klik pada gambar untuk membuka jendela Menu Prediksi. Nomor tiga (3) merupakan Menu Geometri. Klik pada gambar untuk membuka jendela Menu Geometri.

\section{b) Tampilan Antarmuka Grafis Menu Tabel Periode dan Penjelasannya}

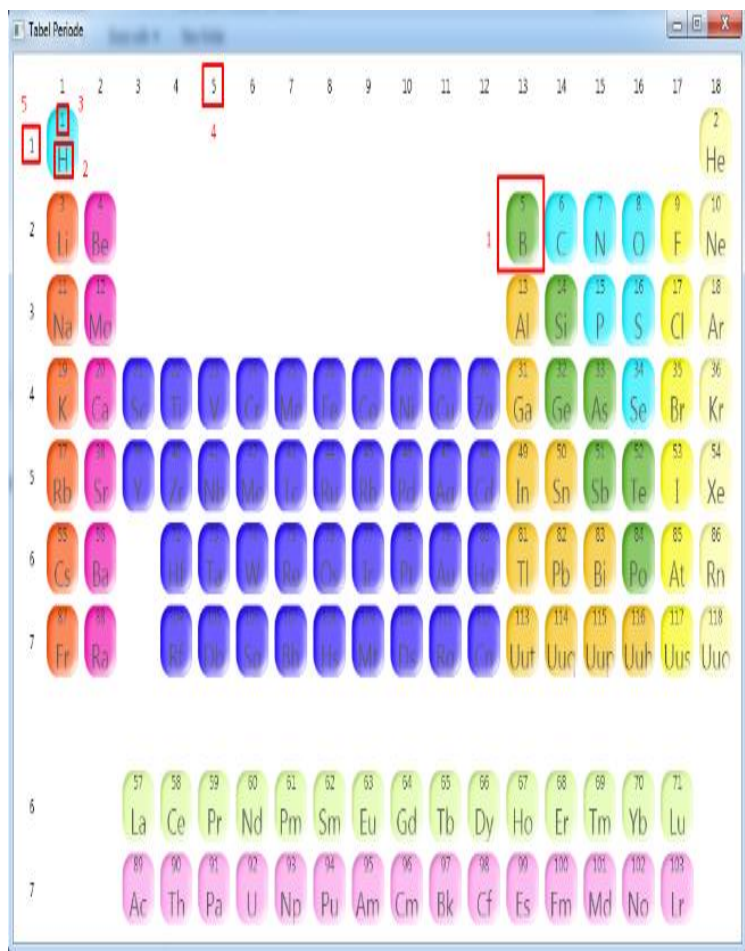

Sumber: dokumen penulis

Gambar 3. Antarmuka Grafis Menu Tabel Periode

Penjelasan gambar:

Nomor satu (1) adalah tombol yang merepresentasikan atom pada tabel periode. Klik pada tombol untuk membuka jendela Informasi Deskriptif Atom. Nomor dua (2) menunjukkan simbol atom. Nomor tiga (3) menunjukkan nomor atom. Nomor empat (4) menunjukkan nomor group atom berdasarkan IUPAC. Atom yang berada di dalam satu group merupakan atom yang satu arah secara vertikal. Nomor lima (5) menunjukkan nomor periode atom. Atom yang memiliki periode yang sama adalah atom dengan arah horizontal.

\section{c) Tampilan Antarmuka Grafis Jendela Informasi Unsur Atom dan Penjelasannya}

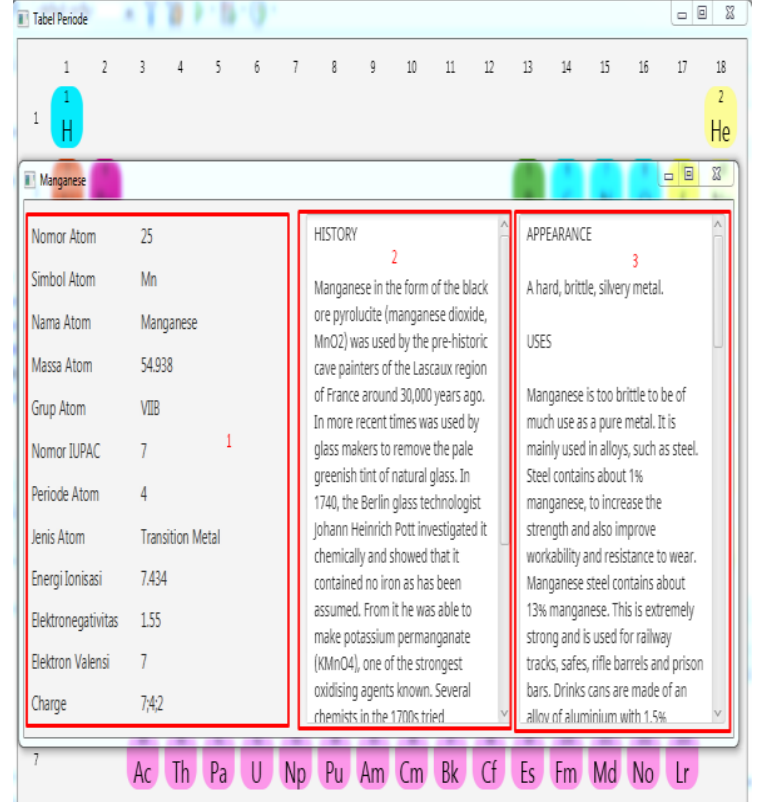

Sumber: dokumen penulis

Gambar 4. Antarmuka Grafis Jendela Deskripsi Atom

Penjelasan gambar:

Nomor satu (1) merupakan informasi atomik element. Nomor dua (2) merupakan informasi sejarah penamaan element dan sejarah tabel periode. Nomor tiga (3) merupakan informasi bentuk fisik, penggunaan, dan lain-lain.

\section{d) Tampilan Antarmuka Grafis Menu Prediksi dan Penjelasannya}

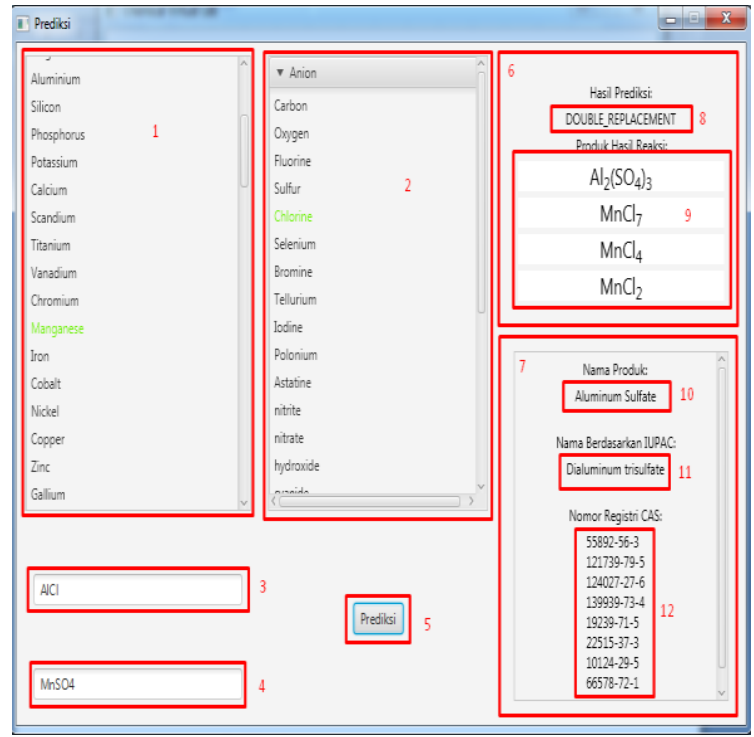

Sumber: dokumen penulis

Gambar 5. Antarmuka Grafis Menu Prediksi

Penjelasan gambar: 
Nomor satu (1) adalah daftar ion kation dengan kombinasi nilai charge yang dimiliki setiap atom. Nomor dua (2) adalah daftar ion anion dengan kombinasi nilai charge yang dimiliki setiap atom. List kation dan anion berfungsi untuk memprediksi reaksi kimia Synthesis. Setelah memilih kation dan anion yang disediakan, seketika itu juga reaksi dan hasil reaksi (produk) ditampilkan pada nomor enam (6). Nomor tiga (3) adalah masukan kompon atau atom sebagai reaktan pertama. Nomor empat (4) adalah masukan kompon atau atom sebagai reaktan kedua. Kedua masukan ini, nomor tiga (3) dan nomor empat (4), dapat memprediksi reaksi kimia Single Replacement, Double Replacement, Combustion, dan Acid/Base. Setelah dua masukan telah diisi, dapat dilanjutkan dengan klik tombol prediksi pada nomor lima (5) untuk menampilkan hasilnya. Nomor lima (5) adalah tombol prediksi. Hanya akan aktif ketika kedua masukan telah terisi. Nomor enam (6) merupakan panel hasil, dimana hasil dari prediksi akan ditampilkan. Nomor tujuh (7) merupakan panel hasil pencarian informasi produk dari reaksi kimia. Nomor delapan (8) merupakan nama jenis reaksi yang diprediksi. Nomor sembilan (9) merupakan produk hasil reaksi kimia. Pada bagian ini, mungkin akan ditampilkan lebih dari satu produk. Hal ini dikarenakan, setiap atom mempunyai kombinasi nilai charge. Beberapa atom memiliki lebih dari tiga nilai (terutama logam transisi). Klik pada bagian ini untuk mencari ketersediaan informasi produk pada NIH atau NCI yang akan ditampilkan pada nomor tujuh (7). Nomor sepuluh (10) merupakan nama berdasarkan penamaan kimiawi (chemistry nomenclature). Nomor sebelas (11) merupakan nama berdasarkan penamaan IUPAC yang didapatkan dari NIH atau NCI. Nomor dua belas (12) merupakan nomor registry CAS (Chemical Abstract Service) yaitu nomor unik yang diberikan kepada setiap kompon oleh salah satu divisi IUPAC.

\section{e) Tampilan Antarmuka Grafis Menu Geometri dan Penjelasannya}

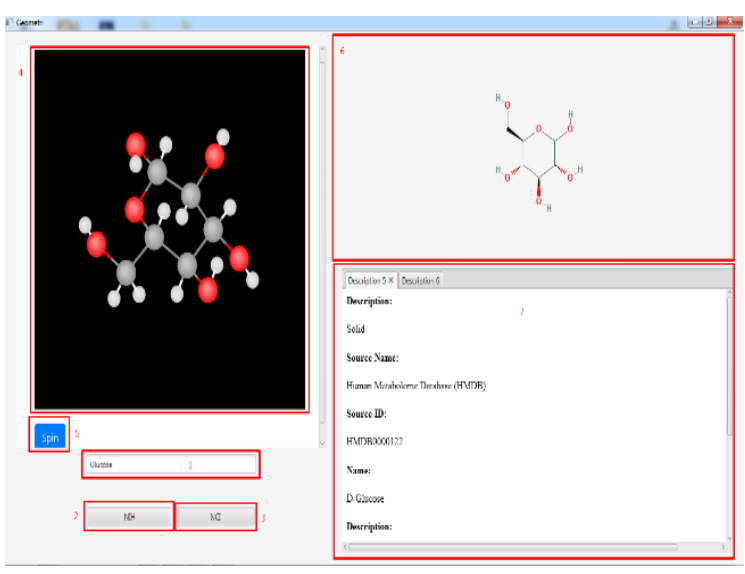

Sumber: dokumen penulis

Gambar 6. Antarmuka Grafis Menu Geometri
Penjelasan gambar:

Nomor satu (1) masukan yang nantinya akan dicari bentuk geometri tiga dimensi, dua dimensi, serta informasi fisik yang deskriptif. Nomor dua (2) adalah tombol pencarian yang bersumber dari NIH. Nomor tiga (3) adalah tombol pencarian yang bersumber dari NCI. Kedua tombol ini, nomor dua (2) dan nomor tiga (3), tidak akan akif sampai masukkan terisi. Nomor empat (4) merupakan panel geometri 3 dimensi. Geometri 3 dimensi ini dapat dikontrol menggunakan mouse. Nomor lima (5) merupakan tombol yang akan memutar bentuk 3 dimensi secara otomatis. Nomor enam (6) merupakan panel 2 dimensi, dimana ditunjukkan geometri 2 dimensi berupa struktur lewis sederhana. Nomor tujuh (7) merupakan panel yang berisi informasi fisik yang deskriptif. Nomor tujuh merupakan log yang memperlihatkan kondisi berhasil atau tidaknya pencarian informasi.

\section{Perangkat keras dan perangkat lunak yang digunakan}

Dalam menjalankan aplikasi ini, beberapa persyaratan harus terpenuhi seperti perangkat keras dan perangkat lunak yang digunakan. Persyaratanpersyaratan tersebut dijelaskan seperti di bawah ini:

Tabel 13. Daftar Persyaratan Perangkat Keras

\begin{tabular}{|c|c|}
\hline $\begin{array}{c}\text { Nama Perangkat } \\
\text { Keras } \\
\end{array}$ & Persyaratan \\
\hline Prosesor & $\begin{array}{c}\text { Pentium II } 266 \mathrm{MHz} \text { atau } \\
\text { yang lebih tinggi }\end{array}$ \\
\hline Memori (RAM) & $\begin{array}{c}256 \mathrm{MB} \text { atau yang lebih } \\
\text { tinggi }\end{array}$ \\
\hline $\begin{array}{c}\text { Ruang } \\
\text { Penyimpanan }\end{array}$ & $\begin{array}{c}100 \mathrm{MB} \text { atau yang lebih } \\
\text { tinggi }\end{array}$ \\
\hline
\end{tabular}

Sumber: dokumen penulis

Tabel 14. Daftar Persyaratan Sistem Operasi

\begin{tabular}{|c|c|}
\hline $\begin{array}{c}\text { Sistem } \\
\text { Operasi }\end{array}$ & Versi Sistem Operasi \\
\hline Windows & $\begin{array}{c}\text { Windows Vista SP2 atau yang } \\
\text { lebih tinggi }\end{array}$ \\
\hline Linux & $\begin{array}{c}\text { Semua Distribusi yang dapat } \\
\text { terpasang Java Runtime } \\
\text { Environment 1.8+ }\end{array}$ \\
\hline Mac OS X & $\begin{array}{c}\text { Mac OS X 10.8.3+ dan 10.9+ } \\
\text { yang berbasis intel }\end{array}$ \\
\hline
\end{tabular}


Sumber: dokumen penulis

Tabel 15. Daftar Persyaratan Perangkat Lunak

\begin{tabular}{|c|c|}
\hline Perangkat Lunak & $\begin{array}{c}\text { Versi atau Jenis } \\
\text { Perangkat Lunak }\end{array}$ \\
\hline $\begin{array}{c}\text { Java Runtime } \\
\text { Environment }\end{array}$ & $1.8+($ Java 8+) \\
\hline Web Browser & $\begin{array}{c}\text { Internet Explorer, } \\
\text { Firefox, Safari }\end{array}$ \\
\hline
\end{tabular}

Sumber: dokumen penulis

\section{KESIMPULAN}

Aplikasi Chemical Virtual Lab diharapkan dapat digunakan sebagai alat bantu dalam memprediksi hasil uji coba suatu senyawa atau campuran bahan-bahan kimia secara virtual dengan tingkat resiko yang rendah namun memiliki tingkat akurasi yang tinggi. Selain itu hasil penelitian ini diharapkan dapat menjadi sarana dalam mendorong penggagas yang lain untuk menuangkan ilmu pengetahuan ke dalam bentuk aplikasi yang informatif serta edukatif. Aplikasi Chemical Virtual Lab dapat memprediksi hasil bentukan molekul unsur atau molekul senyawa atom dalam bentuk virtual.

\section{PENELITIAN LEBIH LANJUT}

Penulis menyadari bahwa hasil penelitian dan perancangan yang telah dibuat masih belum sempurna dan terdapat beberapa kelemahan. Oleh karena itu diperlukan penelitian lebih lanjut yang lebih komprehensif dan terukur agar menghasilkan prediksi yang lebih akurat lagi. Masih banyak hal yang dapat dikembangkan dalam aplikasi ini, yaitu menyempurnakan prediksi reaksi kimia ke arah yang lebih kompleks, menampilkan jumlah kuantitatif dari reaksi kimia, menghasilkan struktur lewis dari formula struktur untuk memberikan prediksi (resonance structure) ikatan paling stabil (lowest energy) serta apakah ikatan atom tersebut berbahaya (biradical) dengan menggunakan pendekatan formal charge.

\section{REFERENSI}

Anisah, E. (2013). KEFEKTIFAN VIRTUAL LABORATORY TERHADAP HASIL BELAJAR SISWA MATERI LARUTAN PENYANGGA DAN HIDROLISIS, 2(2252), 1-6.

Felintina Yuniarti, Pramesti Dewi $\square$, R. S. (2012). PENGEMBANGAN VIRTUAL LABORATORY SEBAGAI MEDIA PEMBELAJARAN BERBASIS KOMPUTER
PADA MATERI PEMBIAKAN VIRUS, $1(1)$, 86-94.

$\begin{array}{lrr}\text { Jaya, } & \text { H. }(2012) . & \text { PENGEMBANGAN } \\ \text { LABORATORIUM } & \text { VIRTUAL UNTUK } \\ \text { VIRTUAL } & \text { LABORATORY } \\ \text { DEVELOPMENT FOR PRACTICUM AND } \\ \text { FACILITATING } & \text { CHARACTER } \\ \text { EDUCATION IN VOCATIONAL HIGH. } \\ \text { Jurnal Pendidikan Vokasi, 2, 81-90. }\end{array}$

Junie, C. (2017). Tabel Periodik Unsur.

Musalwahyuni, Kasmawi, \& Mawarni, S. (2017). Aplikasi Tabel Periodik Unsur Menggunakan Konsep Mind Mapping, 2(2), 1-6.

Nurrokhmah, I. E., \& Sunarto, W. (2013). Pengaruh Penerapan Virtual Labs Berbasis Inkuiri Terhadap Hasil Belajar Kimia, (2252).

Rozi, F., \& Sukmana, F. (2017). Pengembangan aplikasi ektraksi informasi abstrak dokumen skripsi menggunakan javafx, 03, 38-44.

Sabarni. (2014). ATOM dan MOLEKUL BERDASARKAN ILMU KIMIA DAN PERSPEKTIF AL-QURAN. Lantanida Journal, 2(2).

Sari, R. A., Saputro, S., \& Catur, N. (2014). PENGEMBANGAN MODUL PEMBELAJARAN KIMIA BERBASIS BLOG UNTUK MATERI STRUKTUR ATOM DAN SISTEM, 3(2), 7-15.

Sugiana, I. N., Harjono, A., \& Sahidu, H. (2016). Pengaruh Model Pembelajaran Generatif Berbantuan Media Laboratorium Virtual Terhadap Penguasaan Konsep Fisika Siswa pada Materi Momentum dan Impuls, II(2), 6165.

Yulianti, D., \& Khanafiyah, S. (2012). PENERAPAN VIRTUAL EXPERIMENT BERBASIS INKUIRI UNTUK MENGEMBANGKAN KEMANDIRIAN MAHASISWA, 8, 127-134. 